\title{
SILVIO BOTERO partió llevándose mucho de lo mejor de todos nosotros
}

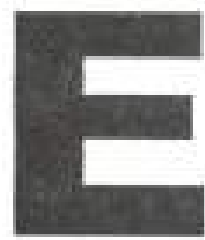

I Comité Intergremial de Caldas que preside del doctor Mario Gómez Estrada, rindió homenaje de admiración y respeto al desaparecido lider caldense Silvio Botero de los Rios, cofundador y miembro permanente del Consejo Superior de la Universidad Autónoma de Manizales, institución que se une a tan merecido reconocimiento con la publicación completa de las palabras de exaltación pronunciadas por su siempre amigo Fernando Londoño Hoyos. El acto tuvo lugar el 11 de Junio de 1998 en el Fondo Cultural del Café.

Cuán generosa se muestra conmigo la vida que me permite rendir homenaje a uno de la caldenses más tipicos y decisivos de nuestro tiempo. Silvio Botero partic llevándose mucho de lo mejor de todos nosotros, pero nos dejó a cambio el riquisimo legado de su 
ejemplo y el consuelo de una amistad que sobrepasará los limites del tiempo

\section{Creo haberlo conocido} desde siempre Es la suya una de esas figuras que no se instalan frente a uno en determinado momento, sino que parecen cocidas intemporalmente al entorno espintual que respiramos Pero habiendolo visto desde que me acuerdo de mi en Manizales y habiendo sentido sin solución de continuidad supresencia apenas distanciada por años que parecian muchos cuando niños y nada cuando su ocaso atormentado, lo vivi para decirlo de algún modo, a partir de nuestra común aventura en el Banco de Caldas y desde entonces. para mi fortuna ya no habria. mos de separarnos más

Era aquél un tiempo critico para Manizales, herida con la pèrdida inminente de las dos cosas que simbolizaban su renovado impetu vital el Banco y la Corporación. Liegué a la Junta Directiva del Caldas, la que compartí con Jorge Echeverri. Eduardo Arango Carios Mejia y Roberto Rivas -creo que ese era el elenco completo de los titulares-en las horas criticas con que se estrenaba la década de los 70

\section{Era aquél un tiempo critico} para Manizales, herida con la pérdida inminente de las dos cosas que simbolizaban su renovado impetu vital...

Eramos tan frágil barquilla que cada lunes cambiaba nuestro destino la consignación grande o chica de nuestro cliente principal la Caja de Sueidos de Retiro de la Policia Nacional Cómo nos sentiamos satisfechos cuando ante el empuje de ese ingreso tan ansiado llegábamos a la cota de los cien millones de pesos en depósitos totales! Pues fue para manejar ese cuasi semi bosquejo de Banco, de contera en crisis, que se acordo para Presidente a Silvio Botero de los Rios, por entonces asegurador y no banquero, oficio respecto al cual, forzado por su talante irreductible pregonaba un noviciado radical y absoluto Tal vez nunca se le agrade- cerà a Silvio y a su inevitable compañero de éxito y angustias, Luis Guillermo Vèlez Palacio, lo que hicieron por esta tierra y esta gente. desde un Banco que tomaron condenado al naufragio Vienen a mi memoria aquellas Juntas inolvidables de los martes de cada quince dias por las que jamas paso una nube de ambición ni un vientecillo de vanidad o de interes personal. El Banco era una cosa propia para todos nosotros que descansabamos sabiendo que al timón iba una mano, tan inexperta como se la quisiera tan limpia y segura como posible

En aquellos dias contagrè a Silvio de mi obsesión y mi entusiasmo por un concepto bancario distinto al que la parroquia colombiana usaba y permitia Le hable de mundos nuevos, tecnologias fantasticas, servicios aqui virgenes. posibilidades infinitas Y Silvio, que era un esceptico racional y un sonador sentimental, cayo en esa trampa de anticipar porvenires y fundar castillos en el aire, el mejor sitio conocido para los castillos de la esperanza. Lo recuerdo conmigo en México y en Rio de Janeiro en aquelios congresos de la Federación Latinoamericana de Bancos 
donde adivinó horizontes inéditos, de donde trajo semillas de futuro y sembró, como era igual por donde pasaba, amistades inextinguibles y admiraciones unánimes.

A muy poco andar, ya era común en el lenguaje del Banco la computación como desafio insoslayable y el quehacer internacional como medio, como objetivo y forma de vida. Superadas las angustias iniciales, afianzados los cimientos y clara la ruta, el de Caldas gozaria en adelante de reputación entre los Bancos, respeto merecido entre el público, adhesión y gratitud entre sus clientes. Debi separarme de ese proyecto fascinante. A pesar del atractivo casi irresistible de compartirlo, con la adición que me suponia venir a mi casa, la de mis padres, que ha sido para todos y por siempre la casa verdadera, otros deberes me privaron del viaje rutinario con el capitán Pérez y de la medalla al viajero distinguido de Tarca que casi nadie me disputaba. Segui de lejos la aventura y cada balance de los marzos me llenaba de intima alegria, y por allá en el fondo del alma de cierta comezón de orgullo, el triunfo de aquello que en cierta romántica manera habia sido mio.

En el Banco de Caldas Silvio aprendió, luchó, triunfó y finalmente fue vencido. Pero esa derrota no fue suya y nos equivocamos todos al entender a medias, 0 al no entender del todo, la gravedad de aquellas horas que partieron en dos la historia de Colombia y particularmente la de Caldas. Me refiero, por supuesto, a los primeros lodos de la avalancha que no tardaría en aplastarnos. Como del fondo de la tierra brotó en manantiales incontenibles una plata fácil, de rara estirpe, atractiva como tesoro impremeditado y como casi todos ellos, dañinísimos cuando no letales.
Halagada la ingenuidad de algunos, rota la voluntad de otros y despertada una extraña y generalizada ambición para enriquecerse sin trabajar o ganar el pan sin el sudor de la frente, los colombianos y muy particularmente los manizaleños abrimos las compuertas de la prudencia y nos dejamos invadir por las audacias y por los audaces. La crisis de 1982 no fue un simple episodio de desorden bancario, como algunos quieren recordarlo. Fue el primer y gran golpe que asestó sobre una sociedad bobalicona el monstruo de la especulación con dinero de maldito origen que nos quitó la brújula primero, nos corrompió después y nos arruinó, para terminar faena. En aquel drama, ya viejo de más de 15 años, hubo desde luego funcionarios públicos tontarrones, depositantes desprevenidos, seudo banqueros funestos. Pero en el fondo de la escena, colma el cuadro el nuevo dinero, el de la mafia, que será desde entonces nuestra cruz, nuestro verdugo y nuestro pecado, todo a la vez

Hasta Manizales se descolgaron financistas de nuevo cuño, y la tomaron por asalto. En el tumulto cayeron muchas cosas de valor $y$ quedaron molidos a palos, como tantas veces el Quijote original, varios de los quijotes nuestros, que aún velaban sus armas en ventas de decencia, de honradez y de decoro, que ellos también imaginaban castillos, Silvio tenía que ser el primero, y como primero fue barrido por la oleada de aquellos infortunios. Desde entonces, el Banco ya no fue más nuestro Banco, y podriamos decir con Garcia Lorca que todos nosotros ya no fuimos nosotros, ni nuestra casa fue ya nuestra casa.

Porque la crisis del 82 no sólo nos quitó la parte de los ahorros privados, el Banco, fábricas que eran emblema y orgullo, y varias 
cosas más Faltaba lo peor. $Y$ ello fue que el doctor

Belisario Bentacur. en la vispera de la crisis fiscal bien merecida por la bancaria, se encontró a la mano la tentaciōn de nuestra bonanza del 85 y sucumbió ante ella Asi quiero decir que aquel Gobierno se llevó lo que pertenecia a los cafeteros y tapó con su sangre el hueco negro del desastre financiero. Fue la última vez que tuvimos un ahorro propio, equivalente a por lo menos 5 billones de pesos de los de hoy. A esta comarca le quitaron, por lo bajo. quinientos mil millones de pesos Como quien dice, con qué construir varios aeropuertos y unas cuantas carreteras y fundar las industrias cuya ausencia lloramos $Y$ todo eso, Banco, fábricas. ahorroy la gente mejor. se la llevo ese viento de miserias sinarrancarnos ungemido $Y$ me temo que no callamos porestoicos Simplemente que tenemos una extraña capacidad para soportar cuaiquier cosa que quieran hacer con nosotros.

Tengo la absoluta certeza de que no por reacción iracunda, que nunca fueron de su estilo sino por honda y serena convicción apareció Silvio Botero entre los jefes caldenses de ese movimien-
Lo recuerdo conmigo en México y en Rio de Janeiro, en aquellos congresos de la Federación Latinoamericana de Bancos donde adivinó horizontes inéditos, de donde trajo semillas de futuro $y$ sembró, como era igual por donde pasaba, amistades inextinguibles $y$ admiraciones unánimes. to politico sin politicos que fue el Nuevo Liberailismo Si aiguna manera de ser y de hacer la vida estaria en las antipodas de la politica que conocemos y practicamos esa seria la de Silvio Lo que demuestra el caracter insular e irrepetible que tuvo el pasc de Luis Carios Galan por la politica nacional. Aquelio fue como un suento coronado por la tragedia, que nunca hemos comprendido. Galàn no fue un hombre, ni un candidato, ni un iluso, ni siquiera un politico en el sentido tradicional del término. Galán fue un testigo de nuesira frenetica carrera hacia el abismo que dio su vida por detenerla, sabiendo que era «vano el esfuerzo y esteril la pasion» como sifuera e! héroe irtedento de Barba Jacob. Qué bien, como simbolo de esa estrella fugaz que rompio un instante las tinieblas de nuestro cielo de miserias, estuvo entonces representado el Nuevo Liberalismo entre nosotros por Silvio Botero Toda la diafanidad de la conducta, el ideal porel ideal el amor sin sombras por Colombia que esa cruzada suponia estaban como impostados en el hombre ideal de nuestra raza Y de todo ese proceso quedará para mi en secreto insoluble como pudo ser intima veraz e intensa la 
amistad de Luis Carlos y Silvio Al primero de ellos lo conoci por 25 años, pues que fui un poco su émulo en la Universidad y luego su amigo y su seguidor por toda su luminosa trayectoria Y no tuve con el mártir, ni de lejos. la indescifrable intimidad que de primera mano me consta desarrollo con Silvio Botero. Porque éste era asi, dueño de una forma irrepetible y si se quiere inexplicable para liegar al corazón de la gente y ganar su voluntad y su confianza. Yello, con tan poca simpatia visible como la suya y no contando con la menor habilidad para el halago ni con aptitud para el servilismo. Pero el hecho, el hecho tozudo e incontrovertible, es que Silvio Botero era un campeon en el arte de conquistar corazones y ganarse la fe de quienes pasando por su lado merecieran esta fe y aquel afecto. Siempre me pregunté, y la vida no dejó ocasión para la respuesta, cómo iba a ser Silvio de capitán victorioso de la politica. Porque en esa materia, como tantos de su generación, no pudo apuntarse más que a las cartas perdedoras. Si hasta llegó a sumarse a la única causa electoral de mi vida. cuando vine a pedir los votos de ustedes para ir a la Constituyente a oponerme a las tragedias que veia venir y que luego llegaron. Aquello fue un hermoso desastre, que tuvo para mi, entre sus mejores alivios, la compañia de un hombre como Silvio Botero de los Rios

Hay una etapa aparentemente oscura en la vida de Silvio Botero. Y fue cuando empujado por el entusiasmo interesado de algunos banqueros, sus amigos, asumió el compromiso de poner a flote una empresa vendedora de maquinaria agricola, que hacia agua por todos los costados. Silvio se dio a la tarea sin tomarse el cuidado de pedir por escrito, con firmas y con sellos, las promesas que le llovieron de los angustiados acreedo. res de aquella sociedad. Mas aun. suscribio cuanto papel le exigieron, siempre con la piadosa explicación de que eran puras formas para tranquilizar superintendentes y aplazar provisiones. Aquél trabajo por poco lo mata por lo intenso y lo quebró de ia manera más injusta. Tuve el honor de servir como Notario de aquél desastre. algo de. consejero y mucho de simple confidente, $Y$ que lección espléndida recibi a cambio de tan poco como pude hacer por Silvio! Yo señores, en este pais y en este tiempo presenciè el espectáculo de un hombre que entregó cuanto tenia por mantener en firme su palabra. Silvio era como uno de aquellos robles debajo de una ruana que remembrara el poeta Robledo Ortiz. Y ese roble moral le dio a los prestamistas que no tuvieron palabra, el ejemplo de cómo por respetarla se llega hasta los limites mismos de la muerte

Entre realizaciones espléndidas y quebrantos indecibles, tuvo Silvio Botero tiempo y energia para la mas grande y bella de las acciones humanas, que no puede ser otra que la de educar Con Ernesto Gutierrez. Ignacio Restrepo y otros compañeros de ideal y de fortuna fue piedra angular de la Universidad Autonoma de Manizales No perece una ciudad que educa y no se puede caer de la memoria agradecida de los hombres la imagen de quien luchó por darles, a traves de la experiencia suprema de la formación y del estudio, una oportunidad sobre la tierra. Al recordar la entrega apasionada con que Silvio hablaba, pensaba y obraba por su Universidad. no nos queda más que admitir que tambien fue suyo el caso de quien murió del corazón, que era de lo que habia vivido.

Y quedaba Hidromiel. De ese proyecto 
alucinante del que oi hablar en mi casa desde cuando era casi un niño, de esa ilusión siempre frustrada, de aquel clamor desatendido. de aquella justicia burlada. $Y$ sin que uno sepa cómo. Silvio Botero reinventó $\mathrm{Hi}$ dromiel. La auténtica, por supuesto. La Central financiable por la propia virtud de sus ventajas y sus números. El proyecto hidroeléctrico modelo, en el que creerian los más grandes constructores del mundo y los mejores financistas, en subsidio de lo poco que en Colombia le creyeron. Qué gratos y nobles recuerdos tengo de aquellos anhos, en los que comprobé que la fe si mueve las montañas. A cada solución le nacia un obstáculo y a cada fórmula un enemigo. Pero allá iba Silvio, Almirante indomeñable en busca de la tierra prometida. Y como el héroe biblico, le estaba reservado el privilegio de llevar su pueblo hasta mirarla, pero sin poner en ella su planta vencedora

Esa politica repugnante, que nos tiene a las puertas del abismo, cobra cualquier precio para vender su mercancia putrefacta. Hidromiel, ya ganadora, era botin reservado para el Patriarca que nos merecemos. Y Silvio estorbaba, y como no era removible por inepto, ni censurable por lerdo, ni perseguible por deshonesto, se confabularon en su contra la injusticia y la calumnia de los atracadores con la cobardia de todos nosotros, para consumar el sacrificio. No fue sólo destituido. Tenía que ser humillado y puesto en la picota pública reservada para los peores truanes y los mayores delincuentes. EI proceso de la Procuraduria General de la Nación mató a Silvio, deshonró a la Procuraduria y nos quitó a todos mucho del sentido del honor que nos quedara La absolución llegó demasiado tarde y será para siempre incompleta. El Dios que es Justicia, cubrirá ciento por uno la iniquidad que cometieron los hombres y cobrará hasta el último céntimo la deuda de los

prevaricadores

Señoras, Señores: Esta ciudad, que en momento de parecida solemnidad llamó mi padre la de la parca memoria y la gratitud recortada, hoy cumple un deber sagrado con su propio porvenir. Emerson y Carlyle demostraron que la ciudad injusta con sus héroes está sentenciada a sufrir la esclavitud de los mediocres Al exaltar la memoria de quien tanta falta nos hace, ejecutamos un acto que nos consuela y reivindica. A Amparo y a sus hijos, que sufrieron el dolor de las persecuciones y los desvíos, pero que llevan en el alma el bálsamo divino de los recuerdos amables y el acicate del ejemplo de una vida plenamente cristiana en el amor, vayan estas paiabras conmovidas y esta expresión de solidaridad en el espiritu. Lo que rompió la injusticia ya lo repara la esperanza. Lo que pisotearon las bajas pasiones hoy lo restablece el afecto de los amigos y el reconocimiento de todos. 


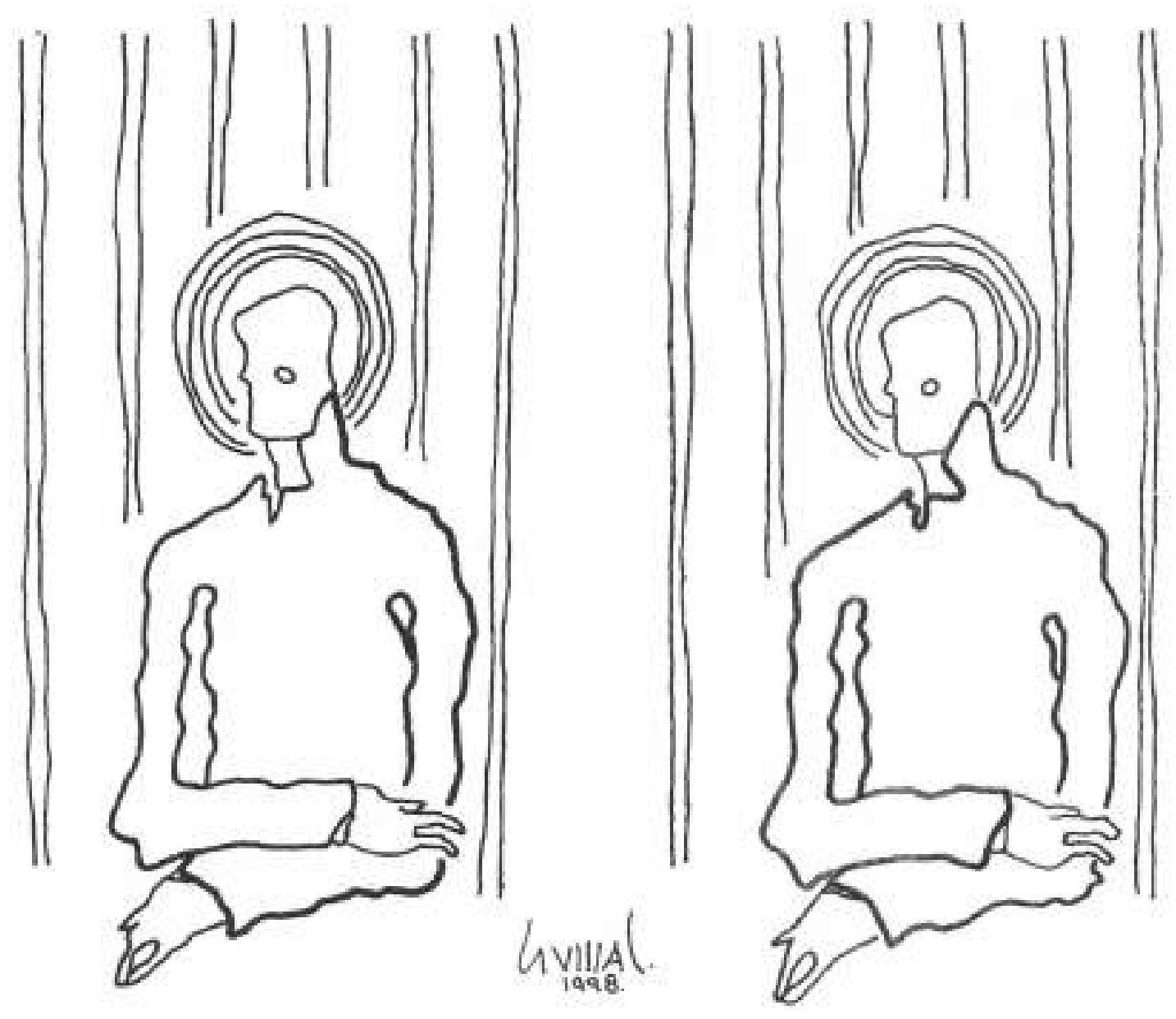

